\title{
CORRELAÇÃO LINEAR E ESPACIAL ENTRE A PRODUTIVIDADE DE FORRAGEM, A POROSIDADE TOTAL E A DENSIDADE DO SOLO DE PEREIRA BARRETO (SP) $)^{(1)}$
}

\author{
Cesar Gustavo da Rocha Lima ${ }^{(2)}$, Morel de Passos Carvalho ${ }^{(3)}$, Luiz \\ Malcolm Mano de Mello ${ }^{(3)}$ \& Ronaldo Cintra Lima ${ }^{(2)}$
}

\begin{abstract}
RESUMO
Em relação aos sistemas de manejo adotados pelo homem, a porosidade total e a densidade do solo são atributos ativamente alterados, refletindo decisivamente sobre a produtividade vegetal agrícola. No ano agrícola de 2005, na Fazenda Bonança, no município de Pereira Barreto, Estado de São Paulo, Brasil, foram analisadas a produtividade de forragem do milho outonal (MSF) no sistema plantio direto irrigado, a porosidade total (PT) e a densidade do solo (DS) em profundidade, em um Latossolo Vermelho distrófico. $O$ objetivo foi estudar a variabilidade e as correlações lineares e espaciais entre os atributos da planta e do solo, visando selecionar um indicador da qualidade física do solo de boa representatividade para produtividade da forragem. Foi instalada a malha geoestatística, para coleta de dados do solo e planta, contendo 125 pontos amostrais, numa área de $2.500 \mathbf{~ m}^{2}$. Os atributos estudados, além de não terem variado aleatoriamente, apresentaram variabilidade dos dados entre média e baixa e seguiram padrões espaciais bem definidos, com alcance entre 6,8 e 23,7 m. Por sua vez, a correlação linear entre o atributo da planta e os do solo, em razão do elevado número de observações, foi baixa. As observações de melhor correlação com a MSF foram a DS1 e a PT1. Entretanto, do ponto de vista espacial, houve excelente correlação inversa entre a MSF e a DS1, assim como entre a DS1 e a PT1. Nos sítios onde a DS1 aumentou $\left(1,45-1,64 \mathrm{~kg} \mathrm{dm}^{-3}\right)$ a MSF variou entre 11.653 e $14.552 \mathrm{~kg} \mathrm{ha}^{-1}$; já naqueles onde diminuiu (1,35-1,45 $\mathrm{kg} \mathrm{dm}^{-3}$ ) a MSF, ficou entre 14.552 e $17.450 \mathrm{~kg} \mathrm{ha}^{-1}$. Portanto, a densidade global, avaliada na camada de 0-0,10 m (DS1), apresentou-se como satisfatório indicador da qualidade física do solo de Pereira Barreto (SP), quando destinado à produtividade de forragem do milho outonal.
\end{abstract}

Termos de indexação: atributos físicos do solo, manejo do solo, forragicultura, nutrição animal.

\footnotetext{
${ }^{(1)}$ Parte da Tese de Mestrado do Programa de Pós-Graduação em Sistemas de Produção, Faculdade de Engenharia - UNESP. Campus de Ilha Solteira. Recebido para publicação em janeiro de 2007 e aprovado em julho de 2007.

${ }^{(2)}$ Mestrando da Faculdade de Engenharia, Universidade Estadual Paulista - UNESP. Campus de Ilha Solteira. Caixa Postal 31, CEP 15385-000 Ilha Solteira (SP). E-mail: etaugustus@aluno.feis.unesp.br

${ }^{(3)}$ Professor Adjunto do Departamento de Fitossanidade, Engenharia Rural e Solos, UNESP. E-mails: morel@agr.feis.unesp.br; mpcarva53@yahoo.com.br; malcolm@agr.feis.unesp.br
} 


\title{
SUMMARY: LINEAR AND SPATIAL CORRELATIONS BETWEEN FORAGE YIELD, TOTAL POROSITY AND BULK DENSITY IN PEREIRA BARRETO, BRAZIL
}

\begin{abstract}
Total porosity and bulk density are strongly affected by soil management, which is reflects directly in agricultural productivity. In 2005, plant attributes were analyzed in an irrigated fall corn crop under no-tillage besides some soil characteristics (total porosityTP and bulk density-BD), in a Haplic Acrustox on the Fazenda Bonança (Dahma Agricultural Company) in Pereira Barreto County, Sao Paulo State, Brazil (20 $40^{\circ} 12$ " latitude S; $51^{\circ} 01$ ' 50 " longitude $W$ ). The purpose of the study was to evaluate the variability, and linear and spatial correlations among the attributes (plant and soil) in order to identify an indicator of soil physical quality for corn forage productivity (CPF). A geostatistical grid was installed to collect soil and plant data, with 125 sample points, over an area of $2.500 \mathrm{~m}^{2}$. The studied attributes did not vary randomly and the variability was medium to low, with well defined patterns. The spatial range varied between 6.8 and $23.7 \mathrm{~m}$. On the other hand, the linear correlations between the CPF with the soil attributes (TP and BD) were low due to the high data number. BD1 and TP1 were best correlated with the CPF. However, concerning the spatial variability, the inverse correlations between CPF and BD1, as well as between $B D 1$ and TP1 were excellent. The BD1 increased (1.45-1.64 $\left.\mathrm{kg} \mathrm{dm}^{-3}\right)$ when the $C P F$ varied from 11.653 to $14.552 \mathrm{~kg} \mathrm{ha}^{-1}$. At the sites where bulk density decreased (1.35$1.45 \mathrm{~kg} \mathrm{dm}^{-3}$ ) the $C P F$ varied from 14.552 to17.450 kg ha-1. Thus, the bulk density in the $0-0.10 \mathrm{~m}$ soil layer proved to be a satisfactory index of the soil physical quality regarding forage yield of fall corn.
\end{abstract}

Index terms: soil physical attributes, soil management, crop forage, animal nutrition.

\section{INTRODUÇÃO}

O milho (Zea mays L.) constitui-se num dos mais importantes cereais cultivados e consumidos no mundo. No Brasil, sua utilização é da ordem de 63,5\% ao consumo animal, 10,0 \% ao industrial, $3,6 \%$ ao humano, $13,6 \%$ à exportação e de $8,7 \%$ a outros, enquanto as perdas representam 0,6\%. O Brasil tem se destacado como o terceiro maior produtor desse grão, porém com baixa produtividade média: $3.352 \mathrm{~kg}^{\mathrm{h}} \mathrm{ha}^{-1}$. Para silagem, o milho é a forrageira de melhor qualidade, sendo muito utilizado na alimentação de gado bovino. Para esse fim, apresentou produtividade média de 20-30 t ha-1 de massa verde para o Estado de São Paulo, equivalendo a 8-12 t ha-1 de massa seca. Entretanto, há casos em que seu potencial de produtividade é superior a $20 \mathrm{t} \mathrm{ha}^{-1}$ de massa seca, dependendo da fertilidade do solo, do cultivar e do clima. Por apresentar sistema radicular com alto potencial de desenvolvimento, os atributos físicos do solo estabelecidos pela relação massa/volume são muito importantes para essa cultura, podendo dificultar a penetração de suas raízes e, conseqüentemente, limitar o adequado aproveitamento dos nutrientes e da água (Fahl et al., 1998; Cruz et al., 2001; Embrapa, 2006a).

A densidade do solo é de grande importância para os estudos agronômicos, pois permite avaliar atributos como porosidade, condutividade hidráulica, difusividade do ar, entre outros, além de ser utilizada como indicador do estado da compactação do solo (Kiehl,
1979; Camargo \& Alleoni, 1997). Por possuir estreita relação com outros atributos, a grande maioria das pesquisas converge para o fato de que, com o seu aumento, ocorre diminuição da porosidade total, macroporosidade, condutividade hidráulica, absorção iônica, assim como o conseqüente aumento da microporosidade e da resistência mecânica à penetração do solo. Esse fato desencadea, no geral, diminuição da produtividade agrícola (Carvalho et al., 1999; Foloni et al., 2003; Mercante et al., 2003; Secco et al., 2005; Mello Filho et al., 2006; Santos et al., 2006).

Por ser o solo um sistema trifásico disperso, a caracterização de sua porosidade total é de grande importância para adoção de um manejo adequado, pois este sistema está estreitamente ligado à dinâmica do armazenamento e do movimento de solutos e de circulação de gases no seu interior, essenciais aos processos bioquímicos das plantas, sobretudo aqueles relacionados com a produtividade vegetal (Kiehl, 1979; Epstein \& Bloom, 2006). Ainda, de acordo com Mercante et al. (2003) e Secco et al. (2005), a porosidade total tem apresentado grande relação com a compactação e a resistência à penetração do solo, as quais tendem a aumentar com a redução do espaço poroso.

A porosidade do solo é referida como ideal quando se apresentar com $0,500 \mathrm{~m}^{3} \mathrm{~m}^{-3}$ do seu volume total, no qual a microporosidade, responsável pelo armazenamento de água, variaria entre 0,250 e $0,330 \mathrm{~m}^{3} \mathrm{~m}^{-3}$. Já a macroporosidade, representada pelo volume de poros responsáveis pela aeração das raízes, ficaria entre 0,170 e $0,250 \mathrm{~m}^{3} \mathrm{~m}^{-3}$. 
As diversas interações entre variáveis do solo fazem com que sua variabilidade espacial, horizontal e, ou, vertical, seja algo inquestionável. Assim, quando ela se apresentar de forma organizada, expressa pela dependência espacial, essa condição passa a ser objeto de estudo da geoestatística, a qual vem apresentando aplicação crescente na avaliação da variabilidade espacial de parâmetros de interesse em ciências agrárias, permitindo a interpretação dos resultados com base na estrutura da sua variabilidade natural, considerando a existência da dependência espacial dentro do espaço de amostragem. Dessa forma, na atualidade constata-se grande implementação da pesquisa da variabilidade espacial, principalmente aquela voltada aos atributos da relação massa/volume do solo e da produtividade vegetal (Carvalho et al., 2002, 2003; Souza et al., 2004a,b; Johann et al., 2004; Andrade et al., 2005; Grego \& Vieira, 2005; Freddi et al., 2006; Mello Filho et al., 2006; Santos et al., 2006).

$\mathrm{Na}$ análise geoestatística, o semivariograma é a representação gráfica do ajuste de modelos matemáticos aos dados observados, de onde se definem parâmetros necessários à estimação de valores para locais não amostrados (Souza et al., 1997). Assim, a variabilidade espacial pode ser representada por mapas, confeccionados a partir de estimativas efetuadas na variável estudada pela técnica da krigagem (Carvalho et al., 2003). Já o semivariograma cruzado é a representação gráfica da dependência espacial existente entre duas variáveis, primária e secundária, que apresentem correlação espacial entre si. Desse modo, pode-se realizar a estimativa de uma das variáveis (primária) por meio da técnica da cokrigagem, que por sua vez é a representação gráfica da estimação (Vieira, 2000). Por outro lado, a validação cruzada é a ferramenta de avaliação dos modelos alternativos de semivariogramas e semivariogramas cruzados que efetuarão a krigagem e a co-krigagem, que são os produtos finais da análise geoestatística.

Diante do exposto, a presente pesquisa, realizada em um Latossolo Vermelho distrófico da Fazenda Bonança, município de Pereira Barreto, objetivou: analisar a variabilidade dos atributos estudados da planta e do solo; analisar as correlações lineares e espaciais entre a produtividade da forragem do milho outonal e a porosidade e densidade do solo pesquisado; e pesquisar, entre os atributos do solo, um indicador da sua qualidade física, visando ao aumento da produtividade da forragem do milho outonal para o local estudado.

\section{MATERIAL E MÉTODOS}

O experimento foi realizado em 2005 na Fazenda Bonança, pertencente à Agropecuária Dahma, localizada no município de Pereira Barreto, Estado de São Paulo, Brasil, na latitude de $20^{\circ} 40$ ' 12 " S e longitude de $51^{\circ} 01^{\prime} 50$ "W, com precipitação e temperatura médias anuais de $1.300 \mathrm{~mm}$ e $24,1^{\circ} \mathrm{C}$, respectivamente. $\mathrm{O}$ tipo climático local é o $\mathrm{A}_{\mathrm{w}}$, segundo classificação de Köppen, caracterizado como tropical úmido com estação chuvosa no verão e seca no inverno. O solo da área de estudo foi um Latossolo Vermelho distrófico típico franco-arenoso, álico, epicompactado, fortemente ácido, classificado conforme Embrapa (2006b).

A planta-teste trabalhada foi o milho safrinha outonal (Zea mays L.), com a finalidade de produção de massa verde para forragem destinada à alimentação bovina. Sua semeadura foi sobre pastagem irrigada (Brachiaria brizantha, cv. Marandu), anteriormente utilizada durante seis anos com bovinos no sistema rotacionado intensivo, dessecando-a com o herbicida glyphosate na dosagem de $1,8 \mathrm{~kg} \mathrm{ha}^{-1}$ (pa), em $20 / 1 / 2005$. O híbrido simples foi o $30 \mathrm{~F} 80$, cuja semeadura foi realizada no dia 10/2/2005, no sistema plantio direto, numa área irrigada por pivô central. Seguiram-se as instruções agrícolas para as principais culturas do Estado de São Paulo (Fahl et al., 1998), tomando-se por base a análise química inicial da fertilidade do solo para fins de rotina, realizada em 3/ 2/2005 (Quadro 1). Assim, o espaçamento entre linhas foi de $0,85 \mathrm{~m}$, com densidade de 5,5 sementes por metro na linha de semeadura. Na adubação de semeadura

Quadro 1. Análise química da fertilidade do solo para fins de rotina do Latossolo Vermelho distrófico de Pereira Barreto (SP)

\begin{tabular}{|c|c|c|c|c|c|c|c|c|c|c|c|c|c|c|c|}
\hline \multirow{2}{*}{ Profundidade } & \multirow{2}{*}{$\mathbf{P}$} & \multirow{2}{*}{ MO } & \multicolumn{4}{|c|}{ pH } & \multirow{2}{*}{$\mathbf{K}^{+}$} & \multirow{2}{*}{$\mathrm{Ca}^{2+}$} & \multirow{2}{*}{$\mathrm{Mg}^{2+}$} & \multirow{2}{*}{$\mathbf{H}+\mathbf{A l}$} & \multirow{2}{*}{$\mathrm{Al}^{3+}$} & \multirow{2}{*}{ SB } & \multirow{2}{*}{ CTC } & \multirow{2}{*}{$\mathbf{V}$} & \multirow{2}{*}{$\mathbf{m}$} \\
\hline & & & $\mathrm{CaCl}_{2}$ & $\mathrm{KCl}$ & $\mathrm{H}_{2} \mathrm{O}$ & $\Delta \mathbf{p H}$ & & & & & & & & & \\
\hline $\mathrm{m}$ & $\mathrm{mg} \mathrm{dm}^{-3}$ & $\mathrm{~g} \mathrm{dm}^{-3}$ & & & & & 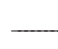 & 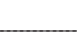 & 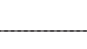 & $\mathrm{mmol}_{\mathrm{c}} \mathrm{dm}$ & & & & - $\%$ & - \\
\hline $0,00-0,20$ & 6 & 18 & 5,6 & 5,2 & 6,5 & $-1,3$ & 1,4 & 15 & 9 & 16 & 0 & 25,4 & 41,4 & 61 & 0 \\
\hline $0,20-0,40$ & 1 & 11 & 4,4 & 4,1 & 5,6 & $-1,5$ & 1,2 & 6 & 4 & 26 & 3 & 11,2 & 37,2 & 30 & 21 \\
\hline $0,40-0,60$ & 1 & 9 & 4,3 & 4,0 & 5,1 & $-1,1$ & 0,6 & 5 & 2 & 26 & 5 & 7,6 & 33,6 & 23 & 40 \\
\hline $0,60-0,80$ & 1 & 7 & 4,2 & 4,0 & 4,8 & $-0,8$ & 0,2 & 4 & 2 & 25 & 6 & 6,2 & 31,2 & 20 & 49 \\
\hline $0,80-1,00$ & 1 & 5 & 4,3 & 4,1 & 4,9 & $-0,8$ & 0,2 & 3 & 3 & 22 & 5 & 6,2 & 28,2 & 22 & 45 \\
\hline $1,00-1,20$ & 1 & 5 & 4,4 & 4,3 & 4,9 & $-0,6$ & 0,3 & 2 & 1 & 20 & 4 & 3,3 & 23,3 & 14 & 55 \\
\hline
\end{tabular}


foram utilizados $320 \mathrm{~kg} \mathrm{ha}^{-1}$ da fórmula 08-28-16. Na de cobertura foram feitas duas aplicações de uréia, uma em 28/2/2005 e a outra em 16/3/2005, ambas nas doses de $106 \mathrm{~kg} \mathrm{ha}^{-1}$ do adubo, assim como uma aplicação de cloreto de potássio, na dosagem de $150 \mathrm{~kg} \mathrm{ha}^{-1}$ do adubo, em 3/3/2005.

Foram definidas as direções dos eixos cartesianos da malha geoestatística experimental, numa área do referido pivô entre dois terraços agrícolas. Assim, o eixo $x$ foi estabelecido em nível, enquanto o $y$ ficou no sentido do declive. Essa malha ficou constituída de um total de 125 pontos amostrais, distribuídos numa área de $2.500 \mathrm{~m}^{2}(50 \times 50 \mathrm{~m})$, com declividade média de $0,025 \mathrm{~m} \mathrm{~m}^{-1}$. O espaçamento entre pontos amostrais utilizado na grande malha foi de $5 \mathrm{~m}$, e na de refinamento, de $1 \mathrm{~m}$. Essa última foi estabelecida com a finalidade de detectar alcances da dependência espacial para espaçamentos menores do que os da grande malha. Dessa forma, as áreas úteis usadas para coleta de dados, tanto do solo quanto da planta, ficaram estabelecidas no entorno de cada ponto amostral, da seguinte forma: (a) na grande malha, com 3,40 m de largura (quatro linhas de semeadura) por 3,40 m de comprimento no sentido da linha, numa área de 11,56 $\mathrm{m}^{2}$; e (b) na de refinamento, com 2,55 m de comprimento (três linhas de semeadura) por $1,00 \mathrm{~m}$ de largura no sentido da linha, numa área de $2,55 \mathrm{~m}^{2}$.

Os atributos do solo, obtidos no entorno de cada ponto amostral, foram a densidade do solo (DS) e a porosidade total (PT), coletados nas profundidades de $0-0,10,0,10-0,20$ e $0,20-0,30 \mathrm{~m}$, em $1 / 5 / 2005$, analisados pelo método do anel volumétrico (Embrapa, 1997). Assim, foram identificados, em função da camada de coleta, da seguinte forma: para a camada de $0-0,10 \mathrm{~m}, \mathrm{DS} 1$ e PT1; para a de 0,10-0,20 m, DS2 e PT2; e para a de 0,20-0,30 m, DS3 e PT3. As análises do solo foram realizadas no Laboratório de Física e Química do Solo da Faculdade de Engenharia de Ilha Solteira (FEIS/UNESP).

$\mathrm{O}$ atributo da planta, coletado no campo, em 30/4/ 2005 , foi a produtividade de massa verde de milho destinado para forragem, cujo estádio fenológico encontrava-se entre o R4 e o R5. Posteriormente, transformou-se em massa seca da forragem (MSF), pela secagem em estufa, a $65^{\circ} \mathrm{C}$, até obtenção da massa constante. A expressão que calculou o atributo trabalhado da planta (MSF), individualmente para cada ponto amostral, foi dada por:

$$
\mathrm{MSF}=(\mathrm{MU} / \mathrm{PA}) \cdot \mathrm{FC} \cdot 10^{4}
$$

em que MSF: produtividade de massa seca da forragem do milho num determinado ponto amostral ( $\left.\mathrm{kg} \mathrm{ha}^{-1}\right)$; MU: massa úmida total das plantas contidas na área designada por tal ponto $(\mathrm{kg})$, que foi de $11,56 \mathrm{~m}^{2}$ para a grande malha e de $2,55 \mathrm{~m}^{2}$ para a de refinamento; PA: área útil do ponto amostral $\left(\mathrm{m}^{2}\right)$; FC: fator de correção da produtividade de massa verde para produtividade de massa seca da forragem, quando tomadas de forma aleatória 10 plantas contidas nas áreas úteis de cada ponto amostral; e 104: fator de conversão de $\mathrm{kg} \mathrm{m}^{-2}$ para $\mathrm{kg} \mathrm{ha}^{-1}$.

Para cada atributo estudado, efetuou-se a análise descritiva clássica, com auxílio do software estatístico SAS (Schlotzhaver \& Littell, 1997), em que foram calculados a média, mediana, valores mínimo e máximo, desvio-padrão, coeficiente de variação, curtose, assimetria e distribuição de freqüência. Posteriormente, realizou-se a identificação dos outliers, efetuando a substituição dos seus valores pelo valor médio dos circunvizinhos contidos na malha. Para testar a hipótese de normalidade, ou de lognormalidade, realizou-se o teste de Shapiro \& Wilk (1965) a $1 \%$. Também, foi montada matriz de correlação, objetivando efetuar as correlações lineares simples para as combinações, duas a duas, entre todos os atributos estudados. Assim, selecionaram-se aqueles de maior correlação linear e que, portanto, poderiam apresentar semivariograma cruzado e a conseqüente co-krigagem. Também, conjuntamente para todas as camadas estudadas do solo, efetuou-se a regressão linear múltipla entre a variável dependente (MSF) e as independentes (atributos do solo), objetivando selecionar aquelas que, nos devidos casos, proporcionariam as melhores relações entre causa e efeito, avaliadas pelo implemento do coeficiente de determinação. Para isso, por intermédio do step wise, foi utilizada a planilha de cálculos do programa Excel.

Isoladamente para cada atributo, foi analisada sua dependência espacial, pelo cálculo do semivariograma simples. Contudo, para aqueles que apresentaram interdependência espacial, calcularam-se também seus semivariogramas cruzados, com base nos pressupostos de estacionaridade da hipótese intrínseca, pelo uso do pacote Gamma Design Software (GS+, 2004).

Os ajustes dos semivariogramas simples e cruzados, em função de seus modelos, foram efetuados pela seleção inicial de: menor soma dos quadrados dos desvios (RSS); maior coeficiente de determinação $\left(\mathrm{r}^{2}\right)$; e maior avaliador da dependência espacial (ADE). A decisão final do modelo que representou o ajuste foi realizada pela validação cruzada, assim como para a definição do tamanho da vizinhança que proporcionou a melhor malha de krigagem e, ou, co-krigagem, realizadas por meio da krigagem em blocos. Para cada atributo, foram relacionados o efeito pepita $(\mathrm{Co})$, o alcance (Ao) e o patamar $(\mathrm{Co}+\mathrm{C})$. A análise do avaliador da dependência espacial (ADE) foi efetuada conforme a seguinte expressão (GS+, 2004):

$$
\mathrm{ADE}=\left[\mathrm{C} /\left(\mathrm{C}+\mathrm{C}_{0}\right)\right] .100
$$

em que $\mathrm{ADE}$ é o avaliador da dependência espacial; $\mathrm{C}$, a variância estrutural; e $\mathrm{C}+\mathrm{C}_{0}$, o patamar. A interpretação proposta para o $\mathrm{ADE}$ foi a seguinte: $\mathrm{ADE} \leq 25 \%$ indica variável espacial fracamente dependente; $25 \%<\mathrm{ADE} \leq 75 \%$ indica variável 
espacial moderadamente dependente; e $\mathrm{ADE}>75 \%$ indica variável espacial fortemente dependente. Por outro lado, sabe-se que a validação cruzada é uma ferramenta destinada a avaliar modelos alternativos de semivariogramas simples e cruzados, que efetuarão, respectivamente, a krigagem e a co-krigagem. $\mathrm{Na}$ sua análise, cada ponto contido dentro do domínio espacial é removido individualmente, sendo seu valor estimado como se ele não existisse. Dessa forma, podese construir um gráfico de valores estimados versus observados, para todos os pontos. O coeficiente de correlação (r) entre tais valores reflete a eficiência do ajuste, dado pela técnica da soma dos quadrados dos desvios, representando a equação de regressão linear em questão. Um ajuste perfeito teria coeficiente de regressão igual a 1 e a linha do melhor ajuste coincidiria com o modelo perfeito, isto é, com o coeficiente linear igual a zero e o angular igual a 1 (GS+, 2004). Assim, trabalhando-se na obtenção do número ideal de vizinhos, foram obtidos, por meio da interpolação, os mapas de krigagem e de co-krigagem, para análise da dependência e da interdependência espacial entre os atributos.

\section{RESULTADOS E DISCUSSÃo}

A variabilidade de um atributo pode ser classificada conforme a magnitude do seu coeficiente de variação (Freddi et al., 2006). No quadro 2, a MSF e a PT1 apresentaram média variabilidade, ao passo que no resto dos atributos ela foi baixa. De modo geral, esses dados ficaram em consonância com os de Carvalho et al. (2002, 2003), Mesquita et al. (2003), Johann et al.
(2004), Souza et al. (2004a,b), Andrade et al. (2005), Grego \& Vieira (2005), Siqueira (2006) e Schaffrath (2006). A variabilidade do solo é produto da interação entre os fatores e os processos de sua formação. Assim, o manejo do solo, quando analisado pela ação que o implemento de preparo proporciona, constitui-se num fato decisivo para o aumento da sua heterogeneidade (Trangmar et al., 1985; Freddi et al., 2006). Portanto, de forma a concordar com esses autores, tanto para a DS quanto para a PT do presente estudo, aliado ao fato do mínimo revolvimento no solo que a semeadora de plantio direto tenha realizado no solo, os maiores coeficientes de variação observados na primeira camada atestaram que o sistema plantio direto proporcionou aumento da heterogeneidade na superfície do solo. Por outro lado, considerando que o teor de matéria orgânica do solo era baixo e decrescente em profundidade (Quadro 1), assim como a compactação anteriormente exercida pelo gado bovino, os menores coeficientes de variação observados nas camadas seguintes atestaram que o sistema plantio direto também pôde contribuir para o aumento da homogeneidade na subsuperfície $(0,10-0,30 \mathrm{~m})$ do solo trabalhado.

Foi observado, na camada superficial do solo (0-0,10 m) elevado enraizamento, originado tanto da pastagem anterior como do próprio milho semeado, denotando aspecto muito poroso e positivo ao solo e, portanto, elevada produtividade da forragem. Esse fato pôde ser comprovado (Quadro 2), uma vez que, do ponto de vista da edafologia, a DS1 foi melhor do que a DS2 e a DS3, assim como a PT1 também o foi em relação à PT2 e PT3. Por outro lado, quando uma variável qualquer possuir distribuição de freqüência normal, a medida de tendência central que melhor a

Quadro 2. Análise descritiva inicial da produtividade de matéria seca da forragem do milho, da densidade e da porosidade total de um Latossolo Vermelho distrófico de Pereira Barreto (SP)

\begin{tabular}{|c|c|c|c|c|c|c|c|c|c|c|}
\hline \multirow{3}{*}{ Atributo $^{(1)}$} & \multicolumn{10}{|c|}{ Medida estatística descritiva } \\
\hline & \multirow{2}{*}{ Média } & \multirow{2}{*}{ Mediana } & \multicolumn{2}{|c|}{ Valor } & \multirow{2}{*}{$\begin{array}{l}\text { Desvio- } \\
\text { padrão }\end{array}$} & \multicolumn{3}{|c|}{ Coeficiente } & \multicolumn{2}{|c|}{$\begin{array}{c}\text { Probabilidade } \\
\text { do teste }^{(2)}\end{array}$} \\
\hline & & & Mínimo & Máximo & & Variação & Curtose & Assimetria & $\operatorname{Pr}<\mathbf{w}$ & DF \\
\hline & & & & & & $\%$ & & & & \\
\hline MSF (kg ha $\left.{ }^{-1}\right)$ & 14.842 & 15.050 & 8.949 & 23.198 & 2.424 & 16,3 & 0,615 & 0,008 & 0,369 & $\mathrm{NO}$ \\
\hline DS1 $\left(\mathrm{kg} \mathrm{dm}^{-3}\right)$ & 1,47 & 1,51 & 1,06 & 1,75 & $1,4.10^{-1}$ & 9,8 & $-0,565$ & $-0,523$ & $5,000.10^{-4}$ & IN \\
\hline $\mathrm{DS} 2\left(\mathrm{~kg} \mathrm{dm}^{-3}\right)$ & 1,67 & 1,67 & 1,55 & 1,77 & $5,1.10^{-2}$ & 3,1 & $-0,705$ & $-0,205$ & 0,090 & $\mathrm{NO}$ \\
\hline DS3 $\left(\mathrm{kg} \mathrm{m}^{-3}\right)$ & 1,69 & 1,69 & 1,48 & 1,90 & $7,0.10^{-2}$ & 4,2 & 0,272 & 0,177 & 0,784 & $\mathrm{NO}$ \\
\hline PT1 $\left(\mathrm{m}^{3} \mathrm{~m}^{-3}\right)$ & 0,367 & 0,354 & 0,254 & 0,530 & $6,3.10^{-2}$ & 17,1 & $-0,656$ & 0,544 & $1,000.10^{-4}$ & IN \\
\hline $\operatorname{PT} 2\left(\mathrm{~m}^{3} \mathrm{~m}^{-3}\right)$ & 0,291 & 0,289 & 0,254 & 0,334 & $1,6.10^{-2}$ & 5,6 & 0,185 & 0,447 & 0,084 & $\mathrm{NO}$ \\
\hline PT3 $\left(\mathrm{m}^{3} \mathrm{~m}^{-3}\right)$ & 0,299 & 0,300 & 0,241 & 0,341 & $2,0.10^{-2}$ & 6,6 & 0,189 & $-0,451$ & 0,078 & $\mathrm{NO}$ \\
\hline
\end{tabular}

(1) MSF: produtividade de matéria seca da forragem; DS: densidade do solo; PT: porosidade total do solo. ${ }^{(2)}$ DF: distribuição de freqüência, sendo NO e IN do tipo normal e indeterminado, respectivamente. 
representa é a média. Dessa forma, para MSF, a distribuição de freqüência foi normal, com valor médio de $14.842 \mathrm{~kg} \mathrm{ha}^{-1}$, ficando tal valor dentro da faixa de produtividade de massa seca do milho, apresentada por Cruz et al. (2001), que variou entre $4.590 \mathrm{e}$ $22.180 \mathrm{~kg} \mathrm{ha}^{-1}$, quando estudados distintos cultivares de milho. Contudo, essa produtividade foi substancialmente superior àquela relatada por Fahl et al. (1998) para o Estado de São Paulo (8.000-12.000 kg ha-1), muito provavelmente devido à irrigação utilizada, uma vez que se tratava de milho safrinha outonal.

Com relação à densidade do solo (Quadro 2), a distribuição de freqüência foi normal para a DS2 e DS3 e indefinida para DS1, sendo esse fato também observado por Johann et al. (2004), Souza et al. (2004a), Grego \& Vieira (2005) e Melo Filho et al. (2006). Por outro lado, concordou em parte com os dados de Carvalho et al. (2002), os quais a apresentaram com distribuição normal e lognormal, indistintamente em profundidade. Seus valores médios foram de $1,47 \mathrm{~kg} \mathrm{dm}^{-3}$ (DS1), $1,67 \mathrm{~kg} \mathrm{dm}^{-3}$ (DS2) e $1,69 \mathrm{~kg} \mathrm{dm}^{-3}$ (DS3), seguindo uma tendência linear positiva, em relação ao aumento em profundidade do solo, indicando que a camada de maior compactação é a que se encontrou entre 0,20 e $0,30 \mathrm{~m}$. Esse fato ficou em consonância com os trabalhos de Souza et al. (2001) e Carvalho et al. (2002), cujos dados também apresentaram aumento da densidade em profundidade no solo, muito provavelmente devido à redução do seu teor de matéria orgânica, ao passo que discordaram dos trabalhos de Carvalho et al. (1999), Grego \& Vieira (2005) e Melo Filho et al. (2006), que encontraram gradiente decrescente para a densidade do solo em profundidade. Os valores indicados no presente trabalho ficaram acima da faixa de variação geral apontada para solos arenosos, mais densos do que os argilosos, relatada entre 1,20 e $1,40 \mathrm{~kg} \mathrm{dm}^{-3}$, e muito próximos dos níveis críticos de densidade do solo indicados por Kiehl (1979) e Camargo \& Alleoni (1997): situados em torno de $1,70 \mathrm{~kg} \mathrm{dm}^{-3}$ - como capazes de afetar o crescimento das plantas, uma vez que tais características impõem barreiras ao seu desenvolvimento adequado (Foloni et al., 2003; Secco et al., 2005).

A porosidade do solo (Quadro 2), a exemplo da densidade, apresentou distribuição de freqüência do tipo indeterminado na superfície (PT1), estando tal fato de acordo com Carvalho et al. (2003). Já na subsuperfície (PT2, PT3), foi observada distribuição normal, concordando com os dados de Carvalho et al. (2003), Mesquita et al. (2003) e Siqueira (2006). Seus valores foram decrescentes em profundidade, sendo de $0,367 \mathrm{~m}^{3} \mathrm{~m}^{-3}$ (PT1), 0,291 $\mathrm{m}^{3} \mathrm{~m}^{-3}$ (PT2) e $0,299 \mathrm{~m}^{3} \mathrm{~m}^{-3}$ (PT3). Assim, esses valores apresentaram-se de forma lógica com os valores de densidade, os quais aumentaram substancialmente em profundidade, denotando evidente estado de maior compactação do solo na segunda e terceira camadas, em relação à primeira, concordando com os trabalhos de Souza et al. (2001), Carvalho et al. (2002) e Melo Filho et al. (2006). Esse fato provavelmente tenha ocorrido devido à grande concentração de raízes da cultura na camada superficial. Assim, os referidos valores de porosidade total, observados em profundidade do solo no presente estudo, ficaram muito próximos do limite inferior estabelecido para o solo agrícola ideal, preconizado por Baver et al. (1973) e Kiehl (1979), que foi de $0,350 \mathrm{~m}^{3} \mathrm{~m}^{-3}$. Dessa forma, isso poderia ter influenciado a capacidade produtiva da planta, de modo a proporcionar redução da sua produtividade. Todavia, a disponibilidade de água parece ter amenizado os efeitos danosos das condições físicas do solo, uma vez que a produtividade de massa seca da forragem (MSF) alcançou o apreciável valor médio de $14.842 \mathrm{~kg} \mathrm{ha}^{-1}$.

Das correlações, entre o atributo da planta e os do solo (Quadro 3), há que se mencionar que todas foram baixas - fato justificável pelo elevado número de observações $(\mathrm{n}=125)$. Aquelas significativas foram para os pares MSF x DS1 $\left(r=-0,143^{*}\right)$, MSF x PT1 $\left(\mathrm{r}=0,199^{* *}\right)$ e MSF x PT2 $\left(\mathrm{r}=-0,190^{* *}\right)$. O primeiro par indicou função decrescente entre causa e efeito, ou seja, quanto menor a densidade do solo, na camada de $0-0,10 \mathrm{~m}$, maior será a MSF. Isso está de acordo com Santos et al. (2006), que observaram a mesma tendência para densidade do solo, quando correlacionada com a produtividade de grãos de milho. O segundo par (MSF x PT1) apresentou correlação positiva entre causa e efeito, indicando o incremento da MSF com o aumento da porosidade total na camada 0-0,10 m. Já no terceiro par (MSF x PT2), por apresentar correlação negativa, ocorreu o inverso do segundo. $\mathrm{O}$ fato ocorrido foi coerente. Ainda que a camada (de $0-0,10 \mathrm{~m}$ ) tenha se apresentado de forma compactada, indicou que o aumento da sua porosidade total implicará também aumento da MSF. Assim, aumentará substancialmente a aeração das raízes do milho e, por conseguinte, a absorção radicular, conforme Santos et al. (2006). Contudo, em relação ao terceiro par, esse fato não pôde ser afirmado, uma vez que a correlação negativa MSF x PT2 ocorreu justamente o contrário do segundo. Portanto, o menor contato solo/raiz diminui a absorção de água e nutrientes pela planta e, consequentemente, da produtividade vegetal, conforme Hakansson et al. (1998). Dessa forma, tal condição pareceu não ser a mais provável, visto que a porosidade total encontrada na segunda camada foi muito baixa e a densidade do solo elevada tornando-se tal fato de difícil explicação. Assim, a MSF, dada em função da PT1 e da PT2, pôde ser estimada pelas seguintes equações de regressão linear simples:

$$
\begin{gathered}
\mathrm{MSF}=1,203 \cdot 10^{4}+7,654 \cdot 10^{3^{*}} \cdot \mathrm{PT} 1 \\
(\mathrm{r}=0,199, \mathrm{p}<0,01) \\
\mathrm{MSF}=6,958 \cdot 10^{3} \cdot \mathrm{PT} 2^{-0,601^{*}} \\
(\mathrm{r}=0,198, \mathrm{p}<0,01)
\end{gathered}
$$


em que MSF é a produtividade de massa seca da forragem do milho $\left(\mathrm{kg} \mathrm{ha}^{-1}\right)$ e PT1 e PT2 representam a porosidade total do solo, nas camadas de 0-0,10 e $0,10-0,20 \mathrm{~m}\left(\mathrm{~m}^{3} \mathrm{~m}^{-3}\right)$, respectivamente.

Da mesma forma, exclusivamente entre os atributos do solo, para o par de maior correlação (PT1 X DS1), tal equação foi:

$$
\begin{gathered}
\text { PT1 }=9,544 \cdot 10^{-1}-3,983 \cdot 10^{-1^{* *}} \cdot \mathrm{DS} 1 \\
(\mathrm{r}=0,913, \mathrm{p}<0,01)
\end{gathered}
$$

em que PT1 é a porosidade total na primeira camada do solo $\left(\mathrm{m}^{3} \mathrm{~m}^{-3}\right)$ e DS1, a densidade do solo na primeira camada $\left(\mathrm{kg} \mathrm{dm}^{-3}\right)$.

Assim, a equação 5 atestou que a diminuição de dois milésimos da DS1 implicou aumento de um milésimo na PT1. De forma análoga, a equação 3 evidenciou aumento de $8 \mathrm{~kg} \mathrm{ha}^{-1}$ na MSF, com o aumento de um milésimo da PT1; e os valores extremos da PT1 (Quadro 2) resultaram nas respectivas estimativas da MSF de 13.974 e $16.087 \mathrm{~kg} \mathrm{ha}^{-1}$. Por outro lado, com relação aos pares PT2 x DS2 ( $\left.r=-0,307^{* *}\right)$ e PT3 x DS3 ( $\left.\mathrm{r}=-0,503^{* *}\right)$, que também foram de correlação negativa, pôde-se constatar, em relação às três camadas pesquisadas, que com o aumento da densidade do solo ocorreu substancial diminuição da porosidade total, estando isso de acordo com Kiehl (1979), Camargo \& Alleoni (1997), Carvalho et al. (1999) e Secco et al. (2005). Finalmente, em relação ao atributo da planta quando estabelecido como variável dependente e aos do solo como variáveis independentes, foi ajustada a seguinte equação de regressão linear múltipla:

$$
\begin{gathered}
\mathrm{MSF}=7070,4+16840,5^{*} \cdot \mathrm{PT} 1-4529,2^{*} \cdot \mathrm{PT} 2 \\
\left(\mathrm{R}^{2}=0,104, \mathrm{p}<0,05\right)
\end{gathered}
$$

em que MSF é a produtividade de massa seca da forragem do milho ( $\left.\mathrm{kg} \mathrm{ha}^{-1}\right)$ e PT1 e PT2 representam a porosidade total, na primeira e segunda camadas do solo $\left(\mathrm{m}^{3} \mathrm{~m}^{-3}\right)$, respectivamente.

A análise geoestatística das krigagens (Quadro 4) evidenciou excelentes semivariogramas, tanto para a planta quanto para o solo. O melhor deles foi ajustado para a DS1, com coeficiente de determinação espacial de 0,906 , enquanto para a MSF ele foi de 0,770 . Porém, todos os atributos pesquisados apresentaram dependência espacial. Desse modo, evidenciaram que suas distribuições no espaço não foram aleatórias, uma vez que a classe de dependência espacial da MSF foi de 73,5\% (moderada) e a do solo variou entre $26,0 \%$ (moderada/DS3) e 89,8 \% (alta/PT1), concordando com os trabalhos de Carvalho et al. (2002, 2003), Souza et al. (2004a,b), Grego \& Vieira (2005), Santos et al. (2006), Schaffrath (2006) e Siqueira (2006), os quais apresentam classes semelhantes de dependência espacial para os mesmos atributos do solo.

Portanto, no presente estudo (Quadro 4), pôde-se constatar que 73,5 \% da variação total da MSF foi explicada pela dependência espacial. Por sua vez, o efeito pepita atribuído aos erros casuais foi de $26,5 \%$. Para todos os atributos, os modelos ajustados foram o exponencial (MSF e PT3), o gaussiano (DS1, DS3 e PT1) e o esférico (DS2 e PT2). Com relação aos atributos do solo, os modelos dos ajustes obtidos pela pesquisa em questão concordaram parcialmente com os de Carvalho et al. (2002), Johann et al. (2004), Souza et al. (2004b), Andrade et al. (2005), Santos et al. (2006), Schaffrath (2006) e Siqueira (2006), uma vez que neles ora um ora outro modelo foi observado. Já com relação ao alcance da dependência espacial, para a MSF ele foi de $11,8 \mathrm{~m}$, ao passo que os valores extremos, para a DS e a PT, variaram entre $6,8 \mathrm{~m}$ (PT2) e 23,7 m (PT3), ficando com valores semelhantes aos encontrados por Carvalho et al. (2002, 2003), Grego

\begin{tabular}{|c|c|c|c|c|c|c|}
\hline $\mathrm{DS} 1$ & $-0,143^{*}$ & - & & & & \\
\hline $\mathrm{DS} 2$ & $0,001^{\mathrm{ns}}$ & $0,152^{* *}$ & - & & & \\
\hline DS3 & $0,104^{\mathrm{ns}}$ & $-0,101^{\mathrm{ns}}$ & $-0,026^{\mathrm{ns}}$ & - & & \\
\hline PT1 & $0,199^{* *}$ & $-0,913^{* *}$ & $-0,129^{*}$ & $0,096^{\mathrm{ns}}$ & - & \\
\hline PT2 & $-0,190^{* *}$ & $-0,044^{\mathrm{ns}}$ & $-0,307^{* *}$ & $-0,029^{\mathrm{ns}}$ & $0,053^{\mathrm{ns}}$ & - \\
\hline PT3 & $-0,068^{\mathrm{ns}}$ & $0,327^{* *}$ & $0,209^{* *}$ & $-0,503^{* *}$ & $-0,310^{* *}$ & $0,140^{*}$ \\
\hline
\end{tabular}

Quadro 3. Matriz de correlação linear simples entre a produtividade de matéria seca da forragem do milho, a densidade e a porosidade total de um Latossolo Vermelho distrófico de Pereira Barreto (SP)

\begin{tabular}{lcccccc}
\hline \multirow{2}{*}{ Atributo $^{(1)}$} & \multicolumn{5}{c}{ Coeficiente de correlação } \\
\cline { 2 - 6 } & MSF & DS1 & DS2 & DS3 & PT1 & PT2 \\
\hline
\end{tabular}

\footnotetext{
(1) MSF: produtividade de matéria seca da forragem; DS: densidade do solo; PT: porosidade total. *, ** e ns: significativo a 5 e $1 \%$ e não-significativo, respectivamente.
} 
Quadro 4. Parâmetros dos semivariogramas ajustados para a produtividade de matéria seca da forragem do milho, densidade e porosidade total de um Latossolo Vermelho distrófico de Pereira Barreto (SP)

\begin{tabular}{|c|c|c|c|c|c|c|c|c|c|}
\hline Atributo(1) $^{(1)}$ & Modelo(2) $^{(2)}$ & $\begin{array}{c}\text { Efeito } \\
\text { pepita } \\
\text { (C0) }\end{array}$ & $\begin{array}{c}\text { Patamar } \\
(\mathrm{Co}+\mathrm{C})\end{array}$ & $\begin{array}{c}\text { Variância } \\
\text { estrutural } \\
\text { (C) }\end{array}$ & $\begin{array}{c}\text { Alcance } \\
\text { (m) } \\
(\mathrm{A} 0)\end{array}$ & $\mathbf{r}^{2}$ & $\mathbf{S Q R} \mathbf{R}^{(3)}$ & $\operatorname{ADE}^{(4)}$ & $\begin{array}{c}\text { Classe de } \\
\text { dependência } \\
\text { espacial }\end{array}$ \\
\hline
\end{tabular}

\begin{tabular}{|c|c|c|c|c|c|c|c|c|c|}
\hline \multirow[b]{2}{*}{$\operatorname{MSF}\left(\mathrm{kg} \mathrm{ha}^{-1}\right)$} & \multicolumn{9}{|c|}{$\gamma(\mathrm{h})$ simples dos atributos } \\
\hline & $\exp$ & $1,250.106$ & $4,715.106$ & $3,465.106$ & 11,8 & 0,770 & $1,667.1012$ & 73,5 & moderada \\
\hline $\operatorname{DS} 1\left(\mathrm{~kg} \mathrm{dm}^{-3}\right)$ & gau & $5,370.10^{-3}$ & $1,934.10^{-2}$ & $1,397.10^{-2}$ & 23,0 & 0,906 & $1,182.10^{-5}$ & 72,2 & moderada \\
\hline $\mathrm{DS} 2\left(\mathrm{~kg} \mathrm{dm}^{-3}\right)$ & esf & $7,260.10^{-4}$ & $2,352.10^{-3}$ & $1,626.10^{-3}$ & 12,9 & 0,707 & $6,287.10^{-7}$ & 69,1 & moderada \\
\hline DS3 $\left(\mathrm{kg} \mathrm{dm}^{-3}\right)$ & gau & $3,700.10^{-3}$ & $5,000.10^{-3}$ & $1,500.10^{-3}$ & 13,9 & 0,706 & $3,570.10^{-7}$ & 26,0 & moderada \\
\hline $\mathrm{PT} 1\left(\mathrm{~m}^{3} \mathrm{~m}^{-3}\right)$ & gau & $3,700.10^{-4}$ & $3,620.10^{-3}$ & $3,250.10^{-3}$ & 11,3 & 0,655 & $3,268.10^{-6}$ & 89,8 & alta \\
\hline $\mathrm{PT} 2\left(\mathrm{~m}^{3} \mathrm{~m}^{-3}\right)$ & esf & $4,300.10^{-5}$ & $2,490.10^{-4}$ & $2,060.10^{-4}$ & 6,8 & 0,780 & $5,576.10^{-9}$ & 82,8 & alta \\
\hline \multirow[t]{2}{*}{ PT3 $\left(\mathrm{m}^{3} \mathrm{~m}^{-3}\right)$} & $\exp$ & $1,360.10^{-4}$ & $3,030.10^{-4}$ & $1,670.10^{-4}$ & 23,7 & 0,400 & $4,727.10^{-8}$ & 55,1 & moderada \\
\hline & \multicolumn{9}{|c|}{$\gamma(\mathrm{h})$ cruzado entre atributos } \\
\hline $\mathrm{MSF}=\mathrm{f}(\mathrm{DS} 1)$ & Gau & $-1,000.10^{-1}$ & $-6,348.101$ & $-6,338.101$ & 17,3 & 0,539 & $3,702.103$ & 99,8 & alta \\
\hline $\mathrm{MSF}=\mathrm{f}(\mathrm{DS} 2)$ & gau & $1,000.10^{-2}$ & 5,900 & 5,890 & 11,7 & 0,217 & $5,280.102$ & 99,8 & alta \\
\hline $\mathrm{MSF}=\mathrm{f}(\mathrm{DS} 3)$ & esf & $1,000.10^{-2}$ & $1,017.101$ & $1,016.101$ & 19,0 & 0,574 & $3,140.102$ & 99,9 & alta \\
\hline $\mathrm{MSF}=\mathrm{f}(\mathrm{PT} 2)$ & esf & $-1,000.10^{-2}$ & $-9,890$ & $-9,880$ & 20,1 & 0,472 & $1,390.102$ & 99,9 & alta \\
\hline $\mathrm{MSF}=\mathrm{f}(\mathrm{PT} 3)$ & gau & $-1,000.10^{-2}$ & $-7,730$ & $-7,720$ & 19,7 & 0,509 & $2,430.102$ & 99,9 & alta \\
\hline $\mathrm{PT} 1=\mathrm{f}(\mathrm{DS} 1)$ & esf & $-1,100 \cdot 10^{-4}$ & $-7,070.10^{-3}$ & $-6,960.10^{-3}$ & 13,7 & 0,648 & $9,322.10^{-6}$ & 98,4 & alta \\
\hline
\end{tabular}

(1) MSF: produtividade de matéria seca da forragem; DS: densidade do solo; PT: porosidade total. ${ }^{(2)}$ exp: exponencial, gau: gaussiano, esf: esférico. ${ }^{(3)} \mathrm{SQR}$ : soma dos quadrados dos resíduos. ${ }^{(4)} \mathrm{ADE}$ : avaliador da dependência espacial.

\& Vieira (2005) e Siqueira (2006), nos quais variaram entre 3,9 e 23,7 m (PT) e entre 1,0 e 13,1 m (DS).

A análise geoestatística das co-krigagens (Quadro 4) indicou que os três melhores semivariogramas cruzados foram para os atributos $\mathrm{PT} 1=\mathrm{f}(\mathrm{DS} 1), \mathrm{MSF}=\mathrm{f}(\mathrm{DS} 3)$ e MSF $=\mathrm{f}(\mathrm{DS} 1)$, respectivamente com coeficientes de determinação espacial de 0,648, 0,574 e 0,539. Também revelou ajuste gaussiano para os atributos $\mathrm{MSF}=\mathrm{f}(\mathrm{DS} 1), \mathrm{MSF}=\mathrm{f}(\mathrm{DS} 2)$ e MSF $=\mathrm{f}(\mathrm{PT} 3)$ e esférico para MSF $=\mathrm{f}(\mathrm{DS} 3), \mathrm{MSF}=\mathrm{f}(\mathrm{PT} 2)$ e PT1 $=\mathrm{f}(\mathrm{DS} 1)$, cujos alcances variaram entre $11,7 \mathrm{~m}[\mathrm{MSF}=\mathrm{f}(\mathrm{DS} 2)]$ e 20,1 m [MSF = f (PT2)], assim como com elevado ADE para todos. Entretanto, os semivariogramas cruzados dos atributos $\mathrm{MSF}=\mathrm{f}(\mathrm{DS} 2), \mathrm{MSF}=\mathrm{f}(\mathrm{DS} 3)$, $\mathrm{MSF}=\mathrm{f}(\mathrm{PT} 2)$ e MSF $=\mathrm{f}(\mathrm{PT} 3)$, por terem apresentado inúmeros lags, tanto no primeiro quanto no quarto quadrante, denotando um aspecto duvidoso entre as variáveis a ponto de indefini-las, se diretas e, ou, inversas, foram tidos como impraticáveis (Figura 2b). Contudo, tal fato não aconteceu com os atributos MSF $=\mathrm{f}(\mathrm{DS} 1)$ e PT1 = $\mathrm{f}(\mathrm{DS} 1)$, os quais apresentaram ótimas relações inversas entre variáveis, com lags apenas no quarto quadrante (Figura 2a,c). Assim, espacialmente, em relação ao atributo $\mathrm{MSF}=\mathrm{f}(\mathrm{DS} 1)$, cujas krigagens simples estão representadas na figura 1a,b, onde ocorreu substancial elevação da densidade do solo na primeira camada (regiões noroeste, sudoeste e sudeste), com valores entre 1,45 e $1,64 \mathrm{~kg} \mathrm{dm}^{-3}$, a MSF variou entre $11.653 \mathrm{e}$ $14.552 \mathrm{~kg} \mathrm{ha}^{-1}$, com média de $13.103 \mathrm{~kg} \mathrm{ha}^{-1}$. Em contrapartida, onde ocorreu substancial diminuição da densidade do solo na primeira camada (regiões norte, nordeste e centro-sul), com valores entre 1,35 e $1,45 \mathrm{~kg} \mathrm{dm}^{-3}$, a MSF variou entre $14.552 \mathrm{e}$ $17.450 \mathrm{~kg} \mathrm{ha}^{-1}$, com média de $16.001 \mathrm{~kg} \mathrm{ha}^{-1}$. Assim, a tendência desses dados concordou com a de Johann et al. (2004) e Santos et al. (2006), cujos mapas de krigagens indicaram que nas áreas de maior compactação do solo a produtividade da planta foi menor, e vice-versa. Portanto, se forem recomendadas práticas de conservação do solo, como adubação verde, escarificação e subsolagem, à região mais compactada, poderá ser obtida para a MSF produtividade média de $16.001 \mathrm{~kg} \mathrm{ha}^{-1}$, em vez dos $13.103 \mathrm{~kg} \mathrm{ha}^{-1}$. Portanto, esse incremento seria 7,8 \% superior ao da média do quadro 2 (14.842 $\left.\mathrm{kg} \mathrm{ha}^{-1}\right)$.

Com respeito à validação cruzada (Quadro 5), para as krigagens simples foi confirmado que a DS1 proporcionou o melhor ajuste semivariográfico, uma vez que se pôde observar o maior coeficiente de 
(a)

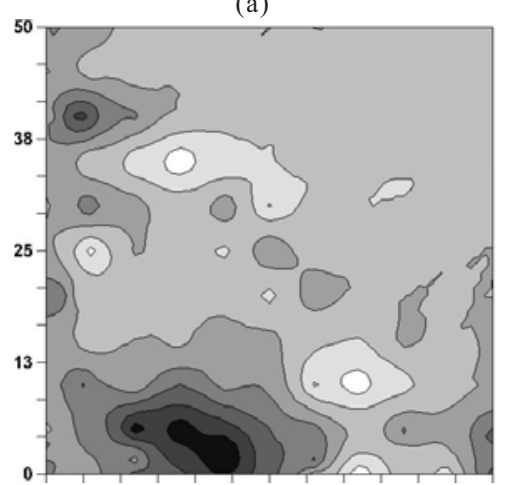

(c)

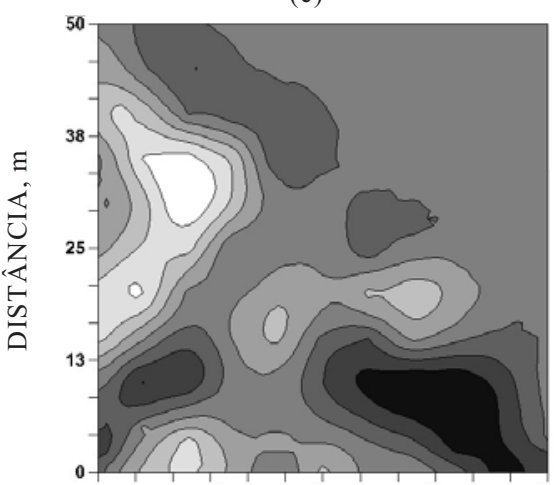

(e)

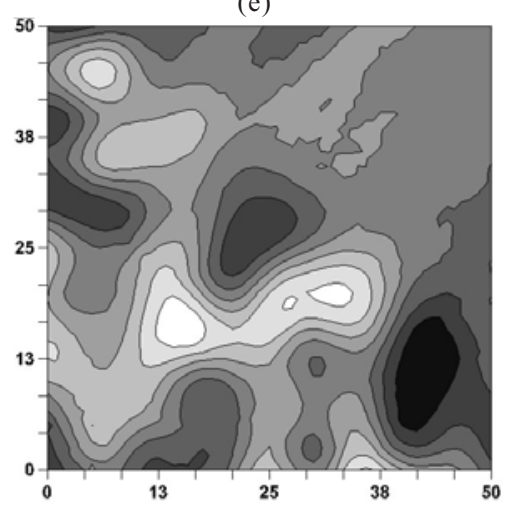

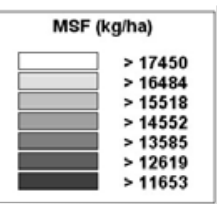

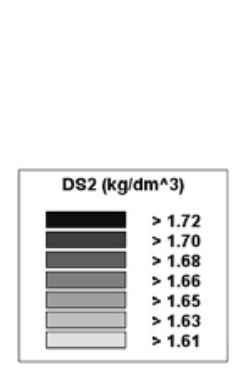

(b)

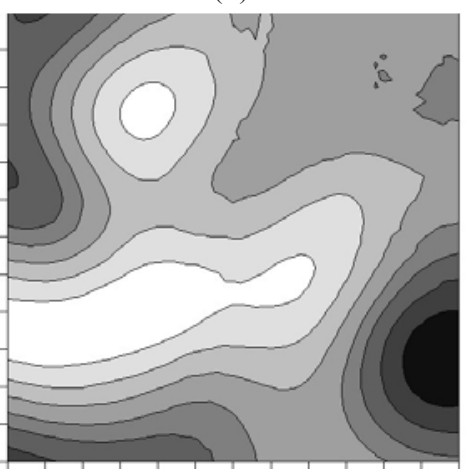

(d)

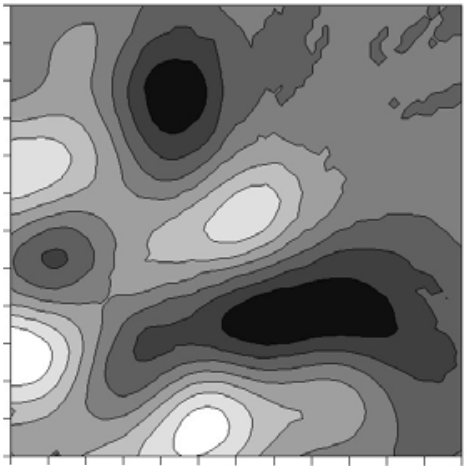

(f)
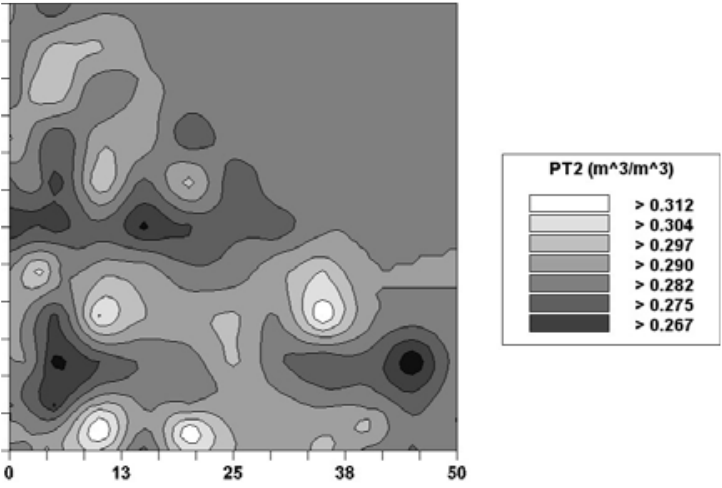

(g)

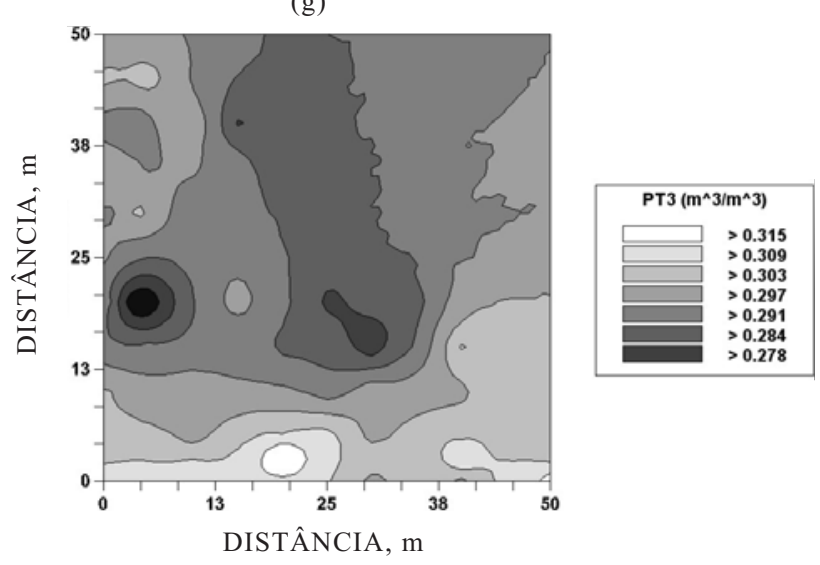

Figura 1. Mapas de krigagem da produtividade de matéria seca da forragem do milho, da densidade (DS1, DS2 e DS3) e da porosidade total (PT1, PT2 e PT3) de um Latossolo Vermelho distrófico de Pereira Barreto (SP). 
$M S F=f(D S 1)$

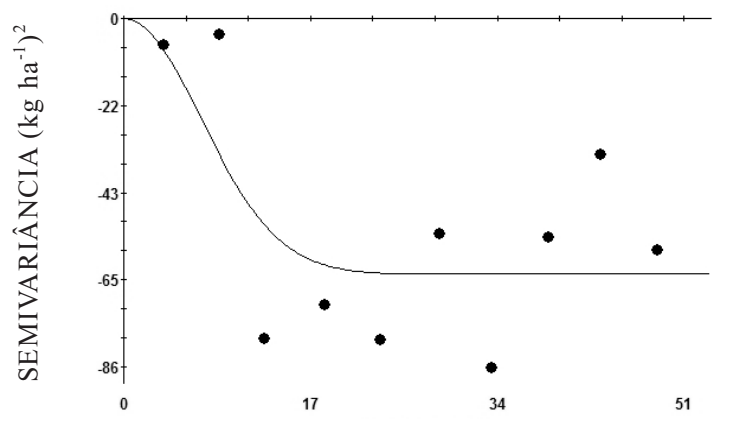

MSF $=\mathbf{f}(D S 2)$

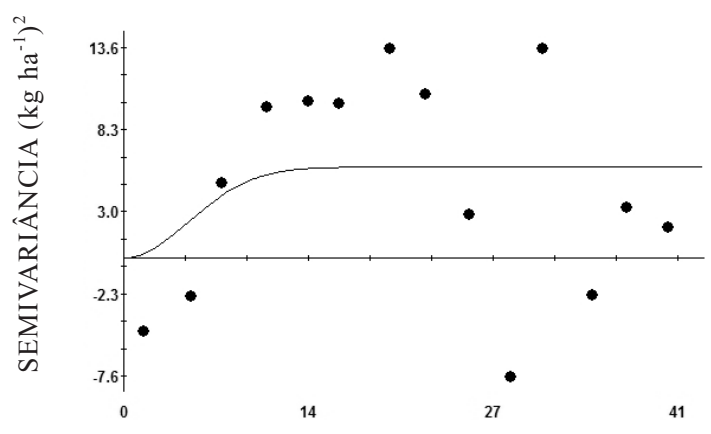

PT1 $=\mathbf{f}($ DS1 $)$

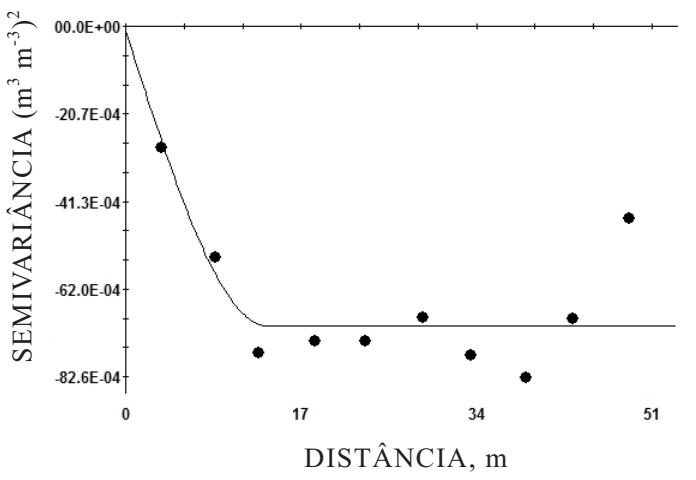

(a)

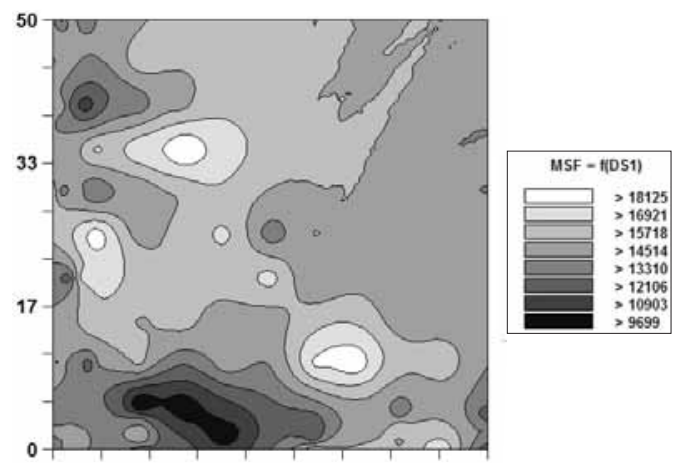

(b)

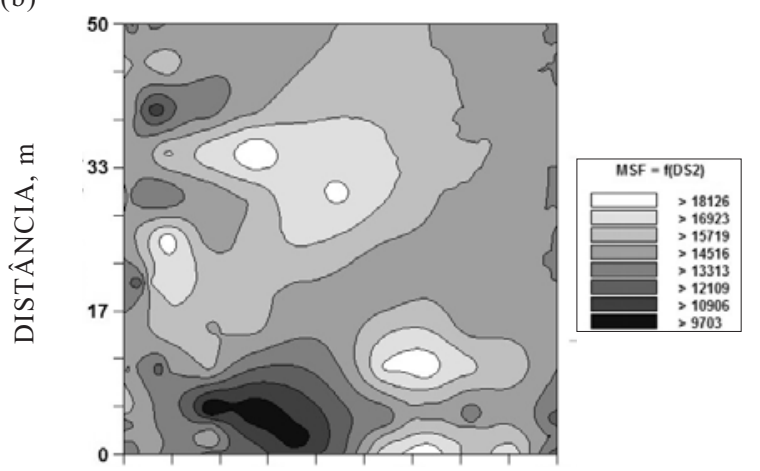

(c)

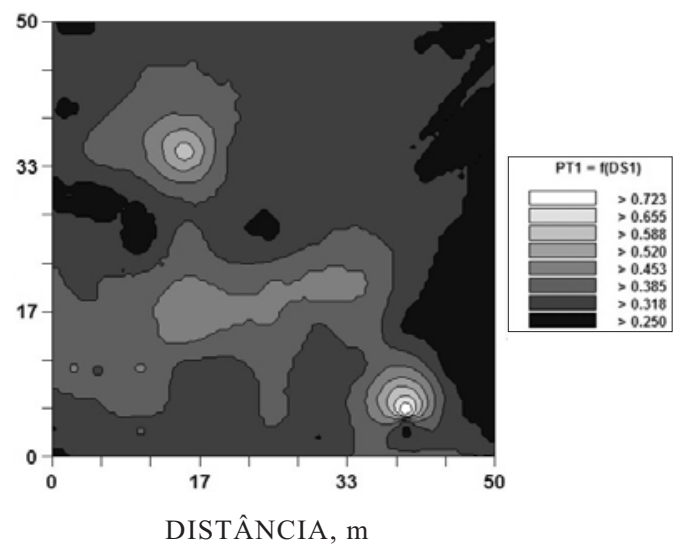

Figura 2. Semivariogramas e mapas de co-krigagem da produtividade de matéria seca da forragem do milho em função da densidade (DS1 e DS2) e da porosidade total (PT1) em função da densidade (DS1) de um Latossolo Vermelho distrófico de Pereira Barreto (SP).

correlação $(r=0,674)$ tanto entre valores observados como entre os estimados desse atributo, com o coeficiente linear (a) tendendo a zero e o angular (b) mais próximo de 1 , fato esse preconizado pelo GS+ (2004). Em relação ao resto dos atributos, com exceção do DS3, de modo geral, todos também tiveram desempenho satisfatório, uma vez que seus coeficientes de correlação variaram entre 0,417 e 0,612, assim como os coeficientes lineares tendendo a zero e os coeficientes angulares entre 0,787 e 0,958. Assim, tais magnitudes foram bastante semelhantes às de Souza et al. (2001), Carvalho et al. (2002, 2003) e Santos et al. (2006).
Já com relação às co-krigagens (Quadro 5), o melhor ajuste foi para o atributo PT1=f(DS1), uma vez que apresentou maior coeficiente de determinação espacial $\left(\mathrm{r}^{2}=0,588\right)$, assim como os apreciáveis valores do coeficiente $a(0,130)$ e do $b(0,641)$, conforme preconizado pelo GS+ (2004). O restante deles apresentou desempenho muito semelhante ao do referido atributo, com valores de $\mathrm{r}^{2}$ entre 0,460 e 0,563, assim como valores do a entre 4.239 e 5.892 e do $b$ entre 0,607 e 0,722. Assim, em virtude de o princípio da convergência das evidências ter mostrado que: (a) 0 DS1 apresentou correlação inversa e significativa 
Quadro 5. Parâmetros das validações cruzadas referentes às krigagens e co-krigagens da produtividade de matéria seca do milho, da densidade e da porosidade total de um Latossolo Vermelho distrófico de Pereira Barreto (SP)

\begin{tabular}{|c|c|c|c|c|}
\hline \multirow{2}{*}{ Atributo $^{(1)}$} & \multicolumn{2}{|c|}{ Erro-padrão } & \multirow{2}{*}{$\begin{array}{l}\text { Coeficiente de } \\
\text { correlação (r) }\end{array}$} & $\mathrm{VO}=\mathrm{a}+\mathbf{b} \cdot \mathrm{VE}^{(2)}$ \\
\hline & Observado & Estimado & & $\mathbf{a}$ \\
\hline
\end{tabular}

\begin{tabular}{|c|c|c|c|c|c|}
\hline $\operatorname{MSF}\left(\mathrm{kg} \mathrm{ha}^{-1}\right)$ & 0,147 & 1,801 & 0,505 & $1,641.10^{3}$ & $8,940.10^{-1}$ \\
\hline $\operatorname{DS} 1\left(\mathrm{~kg} \mathrm{dm}^{-3}\right)$ & 0,103 & 0,097 & 0,674 & $3,560.10^{-2}$ & $9,770.10^{-1}$ \\
\hline $\mathrm{DS} 2\left(\mathrm{~kg} \mathrm{dm}^{-3}\right)$ & 0,116 & 0,038 & 0,612 & $1,111.10^{-1}$ & $9,340.10^{-1}$ \\
\hline $\operatorname{DS} 3\left(\mathrm{~kg} \mathrm{dm}^{-3}\right)$ & 0,326 & 0,068 & 0,127 & $9,145 \cdot 10^{-1}$ & $4,580 \cdot 10^{-1}$ \\
\hline $\operatorname{PT} 1\left(\mathrm{~m}^{3} \mathrm{~m}^{-3}\right)$ & 0,100 & 0,046 & 0,609 & $6,800.10^{-2}$ & $8,220.10^{-1}$ \\
\hline $\mathrm{PT} 2\left(\mathrm{~m}^{3} \mathrm{~m}^{-3}\right)$ & 0,163 & 0,014 & 0,420 & $6,140.10^{-2}$ & $7,870.10^{-1}$ \\
\hline PT3 $\left(\mathrm{m}^{3} \mathrm{~m}^{-3}\right)$ & 0,151 & 0,014 & 0,417 & $1,300.10^{-2}$ & $9,580.10^{-1}$ \\
\hline & \multicolumn{5}{|c|}{$\gamma(\mathrm{h})$ cruzado entre atributos } \\
\hline $\mathrm{MSF}=\mathrm{f}(\mathrm{DS} 1)$ & 0,118 & 1834,472 & 0,466 & $5,892.10^{3}$ & $6,070.10^{-1}$ \\
\hline $\mathrm{MSF}=\mathrm{f}(\mathrm{DS} 2)$ & 0,109 & 1791,057 & 0,563 & $4,238.10^{3}$ & $7,220.10^{-1}$ \\
\hline $\mathrm{MSF}=\mathrm{f}(\mathrm{DS} 3)$ & 0,113 & 1852,676 & 0,460 & $5,841 \cdot 10^{3}$ & $6,130 \cdot 10^{-1}$ \\
\hline $\mathrm{MSF}=\mathrm{f}(\mathrm{PT} 2)$ & 0,118 & 1818,101 & 0,469 & $5,817 \cdot 10^{3}$ & $6,190 \cdot 10^{-1}$ \\
\hline $\mathrm{MSF}=\mathrm{f}(\mathrm{PT} 3)$ & 0,117 & 1748,087 & 0,519 & $4,648.10^{3}$ & $6,940.10^{-1}$ \\
\hline $\mathrm{PT} 1=\mathrm{f}(\mathrm{DS} 1)$ & 0,087 & 0,045 & 0,588 & $1,300 \cdot 10^{-1}$ & $6,410 \cdot 10^{-1}$ \\
\hline
\end{tabular}

(1) MSF: produtividade de matéria seca da forragem; DS: densidade do solo; PT: porosidade total. ${ }^{(2)}$ VO: valor observado e VE: valor estimado.

com o MSF (Quadro 3); (b) o DS1 e o MSF apresentaram ótimos ajustes semivariográficos simples (Quadros 4 e 5; Figura 1a,b); e (c) houve satisfatório ajuste semivariográfico entre o MSF e o DS1, presente na figura $2 \mathrm{a}$, é que despontou o DS1 como indicador da qualidade física do solo estudado, quando destinado à produção de massa seca da forragem de milho outonal para as condições de Pereira Barreto (SP).

\section{CONCLUSÕES}

1. Os atributos estudados, além de não terem variado aleatoriamente, apresentam variabilidade dos dados entre média e baixa, seguindo padrões espaciais bem definidos.

2. A correlação linear entre a produtividade de forragem do milho outonal e a porosidade e, ou, densidade do solo, em razão do elevado número de observações, ainda que tenha sido baixa, é altamente significativa; do ponto de vista espacial, varia sobremaneira, de forma inversamente proporcional.

3. A densidade global, avaliada na camada de 0-0,10 m, apresenta-se como indicador da qualidade física do solo de Pereira Barreto, quando destinado à produtividade de forragem do milho outonal.

\section{LITERATURA CITADA}

ANDRADE, A.R.S.; GUERRINI, I.A.; GARCIA, C.J.B.; KATEZ, I. \& GUERRA, H.O.C. Variabilidade espacial da densidade do solo sob manejo da irrigação. Ci. Agrotec., 29:322-329, 2005.

BAVER, L.D.; GARDNER, W.H. \& GARDNER, W.R. Fisica del suelos. México, Hispano-Americana, 1973. 529p.

CAMARGO, O.A. \& ALLEONI, L.R.F. Compactação do solo e desenvolvimento das plantas. Piracicaba, Escola Superior de Agricultura Luiz de Queiroz, 1997. 132p.

CARVALHO, E.J.M.; FIGUEIREDO, M.S. \& COSTA, L.M. Comportamento físico hídrico de um Podzólico VermelhoAmarelo Câmbico fase terraço sob diferentes sistemas de manejo. Pesq. Agropec. Bras., 34:257-265, 1999.

CARVALHO, M.P.; SORATTO, R.P. \& FREDDI, O.S. Variabilidade espacial de atributos físicos em um Latossolo Vermelho Distrófico sob preparo convencional em Selvíria, estado de Mato Grosso do Sul. Acta Sci., 24:1353-1361, 2002.

CARVALHO, M.P.; TAKEDA, E.Y. \& FREDDI, O.S. Variabilidade espacial de atributos de um solo sob videira em Vitória Brasil (SP). R. Bras. Ci. Solo, 27:695-703, 2003. 
CRUZ, J.C.; PEREIRA FILHO, I.A.; RODRIGUES, J.A.S. \& FERREIRA, J.F., eds. Produção e utilização de silagem de milho e sorgo. Sete Lagoas, Embrapa Milho e Sorgo, 2001. $544 \mathrm{p}$.

EMPRESA BRASILEIRA DE PESQUISA AGROPECUÁRIA EMBRAPA. Introdução e importância econômica do milho. Disponível em: http://www.cnpms.embrapa.br/ publicações/milho\&sorgo. Acesso em: 15 ago. 2006a.

EMPRESA BRASILEIRA DE PESQUISA AGROPECUÁRIA EMBRAPA. Manual de métodos de análise do solo. 2.ed. Rio de Janeiro, 1997.

EMPRESA BRASILEIRA DE PESQUISA AGROPECUÁRIA EMBRAPA. Sistema brasileiro de classificação de solos. 2.ed. Rio de Janeiro, 2006b. 306p.

EPSTEIN, E. \& BLOOM, A. Nutrição mineral de plantas: Princípios e perspectivas. 2.ed. Londrina, Planta, 2006. $403 p$.

FAHL, J.I.; CAMARGO, M.B.P.; PIZZINATO, M.A.; BETTI, J.A.; MELO, A.M.T.; DeMARIA, I.C. \& CANGIANI, A.M., eds. Instruções agrícolas para as principais culturas econômicas. 6.ed. Campinas, Instituto Agronômico, 1998. 396p. (Boletim, 200)

FOLONI, J.S.S.; CALONEGO, J.C. \& LIMA, S.L. Efeito da compactação do solo no desenvolvimento aéreo e radicular de cultivares de milho. Pesq. Agropec. Bras., 38:947-953, 2003.

FREDDI, O.S.; CARVALHO, M.P.; VERONESI JÚNIOR, V. \& CARVALHO, G.J. Produtividade do milho relacionada com a resistência mecânica à penetração do solo sob preparo convencional. Eng. Agríc., 26:113-121, 2006.

GREGO, C.R. \& VIEIRA, S.R. Variabilidade espacial de propriedades físicas do solo em uma parcela experimental. R. Bras. Ci. Solo, 29:169-177, 2005.

GS+: Geostatistics for environmental sciences. 7.ed. Michigan, Plainwell, Gamma Desing Software, 2004. 159p.

HAKANSSON, I.; STENBERG, M. \& RYDBERG, T. Long term experiments with different depths of moldboard plough in Sweden. Soil Till. Res., 46:209-230, 1998.

JOHANN, J.A.; URIBE-OPAZO, M.A.; SOUZA, E.G. \& ROCHA, J.V. Variabilidade espacial dos atributos físicos do solo e da produtividade em um Latossolo Bruno Distrófico da região de Cascavel, PR. R. Bras. Eng. Agríc. Amb., 8:212-219, 2004.

KIEHL, E.J. Manual de edafologia: Relações solo-planta. Piracicaba, Agronômica Ceres, 1979. 264p.

MELO FILHO, J.F.; OLIVEIRA, A.S.; LOPES, L.C. \& VELLAME, L.M. Análise estatística exploratória e variabilidade da densidade do solo em um perfil de Latossolo Amarelo coeso dos tabuleiros costeiros da Bahia. Ci. Agrotec., 30:199-205, 2006.
MERCANTE, E.; URIBE-OPAZO, M.A. \& SOUZA, E.G. Variabilidade espacial e temporal da resistência mecânica do solo à penetração em áreas com e sem manejo químico localizado. R. Bras. Ci. Solo, 27:1149-1159, 2003.

MESQUITA, M.G.B.F.; MORAES, S.O. \& CORRENTE, J.E. Caracterização estatística de variáveis físicas do solo. Acta Sci., 25:35-44, 2003.

SANTOS, M.L.; CARVALHO, M.P.; RAPASSI, R.M.A.; MURAISHI, C.T.; MALLER, A. \& MATOS, F.A. Correlação linear e espacial entre produtividade de milho (Zea mays L.) e atributos físicos de um Latossolo Vermelho distroférrico sob plantio direto do Cerrado Brasileiro. Acta Sci., 28:313-321, 2006.

SCHAFFRATH, V.R. Variabilidade espacial de propriedades físicas do solo e de variáveis de plantas daninhas em sistemas de manejo de solo. Maringá, Universidade Estadual do Paraná, 2006. 91p. (Tese de Doutorado)

SCHLOTZHAVER, S.D. \& LITTELL, R.C. SAS System for elementary statistical analysis. 2.ed. Cary, 1997. 905p.

SECCO, D.; DA ROS, C.O.; SECCO, J.K. \& FIORIN, J.E. Atributos físicos e produtividade de culturas em um Latossolo Vermelho argiloso sob diferentes sistemas de manejo. R. Bras. Ci. Solo, 29:407-414, 2005.

SHAPIRO, S.S. \& WILK, M.B. An analysis of variance test for normality: Complete samples. Biometrika, 52:591-611, 1965.

SIQUEIRA, G.M. Variabilidade de atributos físicos do solo determinados por métodos diversos. Campinas, Instituto Agronômico, 2006. 163p. (Tese de Mestrado)

SOUZA, L.S.; COGO, N.P. \& VIEIRA, S.R. Variabilidade de propriedades físicas e químicas do solo em pomar cítrico. R. Bras. Ci. Solo, 21:367-372, 1997.

SOUZA, Z.M.; MARQUES JÚNIOR, J. \& PEREIRA, G.T. Variabilidade espacial de atributos físicos do solo em diferentes formas do relevo sob cultivo de cana-de-açúcar. R. Bras. Ci. Solo, 28:937-944, 2004a.

SOUZA, Z.M.; MARQUES JÚNIOR, J.; PEREIRA, G.T. \& BENTO, M.J.C. Variabilidade espacial de atributos físicos de um Latossolo Vermelho sob cultivo de cana-de-açúcar. R. Bras. Eng. Agríc. Amb., 8:51-58, 2004b.

SOUZA, Z.M.; SILVA, M.L.S.; GUIMARÃES, G.L.; CAMPOS, D.T.S.; CARVALHO, M.P. \& PEREIRA, G.T. Variabilidade espacial de atributos físicos em um Latossolo Vermelho Distrófico sob semeadura direta em Selvíria (MS). R. Bras. Ci. Solo, 25:699-707, 2001.

TRANGMAR, B.B.; YOST, R.S. \& UEHARA, G. Application of geostatistics to spatial studies of soil properties. Adv. Agron., 38:45-94, 1985.

VIEIRA, S.R. Geoestatística em estudos de variabilidade espacial do solo. In: NOVAIS, R.F.; ALVAREZ V., V.H. \& SCHAEFER, C.E.G.R., eds. Tópicos em ciência do solo. Viçosa, MG, Sociedade Brasileira de Ciência do Solo, 2000. v1. p.1-54. 